\title{
DA PRESERVAÇÃO À FLEXIBILIZAÇÃO
}

Bismarck Duarte Diniz*

RESUMO: O tema flexibilização é recorrente e avança com olhar critico ao processo de mudanças questionando os paradigmas que levam a desregulamentação descaracterizando a lógica da preservação jurídico-social do trabalhador.

ABSTRACT: The subject flexibilization is recurrent and advances to the process of changes questioning the paradigms that take the deregulation, and depriving logic characteristics of workers' legal-social preservation.

RESUMEN: El tema flexibilización es recurrente y avanza con mirar crítico al proceso de los cambios que cuestionan los paradigmas que conducen a la desregulación, decaracterizando la lógica de la preservación legal-social del trabajador.

PALAVRAS-CHAVES: Flexibilização. Paradigma. Globalização. Neoliberalismo.

KEY-WORDS: Flexibilization. Paradigm. Globalization. Neoliberalism.

PALABRAS-LLAVES: Flexibilización. Paradigma. Globalización. Neoliberalismo. 
Os movimentos da classe trabalhadora por um reconhecimento mais amplo de seus direitos individuais e sociais foram, e ainda são, uma realidade. A história do sindicalismo tem demonstrado, nos seus vários períodos, as lutas e reivindicações dos trabalhadores para assegurar melhores condições de vida, tentando, através do reconhecimento de direitos fundamentais, diminuir a exploração do homem pelo homem.

O momento que vivemos assemelha-se à questão social surgida quando a força muscular do homem pôde ser substituída pela máquina. Os postos ocupados por vários trabalhadores passaram a necessitar de um número menor de trabalhadores, que, com o auxílio da máquina, desempenhavam o mesmo trabalho. Isso ocasionou um processo de urbanização e desarticulação social, provocando o desemprego agrícola e artesanal, atividades nas quais trabalhava a maioria da população. Houve uma crescente exploração dos trabalhadores, que eram em número superior às necessidades nas fábricas, contribuindo para o empobrecimento da população. Nasciam a classe capitalista e a classe proletária sob o silêncio e proteção do Estado Liberal, que, sob o aspecto formal, postulava a garantia da liberdade e a igualdade.

Vejamos. O estabelecimento dos chamados direitos fundamentais do homem, como a liberdade, a igualdade e a fraternidade foi ratificado pela Assembléia Nacional da França, quando da Declaração dos Direitos do Homem e do Cidadão, em 1789, como forma de assegurar à burguesia o exercício de seus direitos, principalmente o de propriedade[al1], sem interferência por parte de qualquer pessoa ou entidade, inclusive o próprio Estado. Acerca da defesa dos direitos individuais do trabalhador, não houve por parte da Declaração Francesa qualquer tipo de regulamentação que restringisse o princípio de liberdade do homem para contratar os serviços de outro homem, para não romper com as idéias individualistas e liberais predominantes neste período, e que se estenderiam ao século XIX.

A Declaração dos Direitos do Homem e do Cidadão fixou os princípios do direito individual e do liberalismo econômico e político ${ }^{1}$. As normas de direito nela presentes protegiam os interesses da Nação e dos indivíduos particulares, mas não reconheciam a liberdade de coalizão, que foi proibida pela Lei Le Chapelier, de 14 de junho de 1791.

\footnotetext{
'Neste viés, Floriano Corrêa Vaz da Silva pondera que "o individuo é colocado no centro do ordenamento estatal, sendo ao mesmo tempo fonte de ordenamento mesmo (principio da soberania popular) e destinatário das suas nomas, normas destinadas sobretudo a garantir a liberdade e a igualdade dos particulares perante o Estado" (SILVA, 1977, p. 13).
} 
A Revolução Industrial promoveu profundas mudanças nas relações de trabalho. Tivéssemos alguma testemunha daquelas alterações para prestar seu depoimento, certamente dela ouviríamos que houve desemprego, e sem qualquer proteção por parte do Estado, quando Édison inventou a lâmpada e as fábricas de velas perderam boa parte do mercado consumidor, ou quando Ford colocou os automóveis nas ruas e as fábricas de carroças fecharam, ou quando Graham Bell pôs a funcionar o telefone e a telegrafia perdeu grande parte de sua mão-de-obra. No futuro, quando dobrar o prímeiro século do terceiro milênio, alguma crise social grave deverá estar por aí, desempregando, por novos conflitos. Este é o retrato cíclico da história da humanidade.

Vivemos a era do mundo globalizado ${ }^{2}$, que é um fenômeno econômico que tem atingido a todos, sobretudo após o final da Segunda Grande Guerra. DE MASI (1999, p. 186 passin) afirma que uma houve uma dezena de processos de globalização; contudo, para efeitos didáticos, elencaremos quatro:

a) a primeira foi a do Império Romano dominando o mundo conhecido do Oriente;

b) a segunda, a das grandes descobertas dos séculos XIV e XV, no apogeu de Portugal e Espanha;

c) a terceira, a do liberalismo e das mudanças sociais do século XIX, geradoras, mais tarde, da doutrina social da Igreja, marcada pela Encíclica Rerum Novarum, de Leão XIII;

d) a que vivemos registra a presença das transnacionais, a cosmosociedade de que fala Collierd.

Á medida que a economia deixou de depender da produção do solo, ela deixou de ser economia nacional. A partir do momento em que ela passou do solo para a ciência, para a tecnologia e para as telecomunicações, a terra arável, as fronteiras, o mar e a terra perderam a importância que tinham, e a economia passou a ser parte de um processo mundial de globalização ${ }^{3}$.

\footnotetext{
2 Entende Antonio Rodrigues de Fretas Jủnior que a globalização é "como um processo de intensificaça das relaçôes sochais mundiais, decorrentes da unificação dos mercados e da intemacionalização dos processos produtivos, ao ponto de aproximar distâncias, homogeneizar expectativas e imaginários culturais, bem como subsumir o poder soberano do Estado-Naçäo a uma teia progressivamente complexa de compromissos internacionais e de politicas traçados ao nível de organismos e de arenas transnacionais" (FREITAS JÚNIOR., 1997, p. 72).

"Faz-se necessário pontuar que essa situação afeta o processo de tomada de decisöes pelo Estado, mutas vezes, resultantes de acordos com órgâos técnicos, $\mathrm{em}$ relaçăo às quais não há forma de controle democrático. Não penso apenas no Brasil, mas também nos técnicos burocráticos da União Européia, en grande parte, mais poderosos que os reptesentantes politicos. É a análise de José Eduardo Faria: "Pot isso mesmo, uma outra importante faceta desse processo de recomposiçăo do sistema de poder do Estado-naça säo as recorrentes discussões sobre o sentido, o alcance e o espaço da democracia representativa no âmbito da economia globalizada $(.$.$) e, por fim, sobre o caráter cada vez mais difuso$ e menos transparente da elaboraçăo das regras jurídicas em matéria econômica, monetária, fiscal, cambial, industrial e comercial" (FARIA, 1998, p. 28).
} 
A globalização da economia não é apenas um conceito, e sim o resultado de transformações fundamentais na economia mundial. Mesmo nos casos em que países continuaram a conservar sua qualidade de Nação, eles começaram a transferir setores de suas economias para mãos privadas, porque a privatização não é apenas um conceito, é resultado de um processo.

Vivemos numa fase de grandes transformações muitas vezes apresentadas sem justificação ética, moral ou paradigmaticamente justas ${ }^{4}$.

Uma das crenças mais perversas do neoliberalismo, que agride a memória social da humanidade, é que o direito do trabalho constitui um anacronismo em si mesmo e que o avanço do capitalismo em um mundo globalizado somente se torna possível mediante o retorno à contratação da força de trabalho pelas regras do direito civil: ao invés da oxigenação do princípio da proteção, o império da autonomia da vontade.

Esquecemos que as desigualdades socioeconômicas, a pretexto do exercício da autonomia da vontade, não promovem a liberdade entre os homens, mas acirram a opressão do mais forte sobre o mais fraco e atentam contra a dignidade humana.

Desta forma, o jargão ideologia sem ideologia está implícito a razão de ser do princípio da proteção; os titulares do poder econômico-financeiro se convertem em forças produtivas; os trabalhadores, em contingentes de insatisfações; as demissŏes desmotivadas, em cstratégias de políticas industriais; o desemprego, em políticas de compensaçōes de corajosos planos de desenvolvimento. $\mathrm{E}$ assim a flexibilidade ingressa soberana no nosso cotidiano.

Quero frisar que os argumentos neoliberais para a flexibilidade do Direito do Trabalho não se encontram ideologicamente imaculados, seja no plano dos paradigmas ${ }^{5}$, seja no plano dos fatos.

Impõem-se ao irreversível processo de capitalização das relaçōes humanas, que expressam a conformidade política para com uma específica

\footnotetext{
${ }^{4}$ Segundo Marco Aurélio Garcia "a crise do taylorismo/fordismo é resultado também do desinteresse pelo trabalho, cm que o trabalhador que conquistou salário, prefira mais qualidade de rida do que luta pelas conquistas (absenteísmo-resistência). Assim, as mesmas razôes que impulsionaram a adoçâo, agora impulsionam o abandono do taylorismo/fordismo, com o objetivo de aumentar a produtividade. Assim, nāo se pode falar numa contínua luta de classes nos moldes dos séculos XIX e XX" (GARCIA, 1992, p. 97). Embora se possa admitir o toyotisno como reação à resistência do trabalhador organizado, é importante tessaltar que, ao contrário do taylorismo/fordismo, no toyotismo o trabalhador toma-se um déspota de si mesmo. Elé é instigado a se auto-recriminar e a puxir-se caso sua produção não atinja a chamada qualidade total. Ele trabalha em grupo, em times ou células de produção. $O$ taylorismo e o fordismo tinham uma concepça muito linear, na qual a getếcia cientifica elaborava e o trabalhador manual executava. $O$ toyotismo percebeu a importância de deixar florescer o saber intelectual do trabalho através cos Circulos de Controle da Qualidade, aptopriando-se dos resultados.

"A noģo de paradigma transportada para as Ciencias Sociais, comportou a abrangência do paradigma aplicado nas Ciências Exatas e a consensualização de pontos de vista alcançados na vigência de paradigmas precedentes, do que tesultaram proposiçóes $\mathrm{em}$ direção ao reconhecimento da natureza, necesariamente préparadigmática, dos modelos teóricos no campo das Ciencias Sociats.
} 
etapa desse processo, o mais desumano de todos eles, concernente ao momento histórico em que se propõe a livre circulação do capital no mundo sem quaisquer constrangimentos institucionais.

As alterações que vêm ocorrendo na atualidade levam a uma das principais preocupações enfrentadas pela sociedade e pelos governos, o desemprego, que pode ser comparado à questão social surgida após a Revolução Industrial, na medida em que os antigos paradigmas do processo produtivo são substituídos por outros ${ }^{6}$.

Os fatos dessa crise hodierna podem ser atribuídos à globalização da economia, a uma evolução tecnológica que revoluciona as formas de trabalho, alterando o status quo dos profissionais em geral, à modificação da forma de Estado tradicional, onde há uma crescente regionalização, com formação de blocos e integração entre países, à falta de políticas sociais compativeis com as mudanças geradas e às necessidades emergentes, entre outras.

Muito se tem dito sobre a necessidade de flexibilizar as relações trabalhistas, que o engessamento que impõe a legislação pátria serve como impedimento às novas contratações, à ampliação da oferta de empregos no país. É verdade que é necessário atualizar a legislação, inclusive flexibilizá-la, já que o Brasil, como membro do MERCOSUL, e os demais Estados-Membros", deverá harmonizar a legislação trabalhista para oportunizar igualdade entre os trabalhadores do bloco. E sem flexibilizar, possivelmente, será impossível ${ }^{8}$.

É importante não esquecer, porém, o ensinamento histórico da exploração do homem trabalhador, quando da busca do lucro exacerbado por parte dos empregadores. $O$ princípio protetor constitui a própria essência do Direito do Trabalho. De fato, foi a partir da idéia da intervenção do

\footnotetext{
- FREITAS JÚNIOR explica que "além de tudo o que se afirmou anteriomente con respeito à crise do Direito do Trabaho, protecionista, característico da experiência juridica nos paises de welfare state, $\delta$ sugestiva, do momento de ruptura paradigmática en que acredito que nos encontremos, a maneira pela qual algumas das preposiçǒes que caracterizaram a dogmática juslaborista até o início dos anos oitenta estão a experimentar um gradual esvaziamento $\mathrm{em}$ seu apelo doutrinátio. Tenho em mente, por exemplo, as conhecidas formulas da inalterabilidade in pejus do ajuste integrante do contrato de trabalho, a regra matriz do favor laborus, entre outras tantas que compuseram a summa principia do juslaboralismo. Não quero com isso sugerir que esses postulados tenham sido definitivamente superados. Ao me deter sobre a perda de seu apelo doutrinário, exposto a sucessivas objeçōes e derrogaçōes, estou a sustentar, bem ao contrário, que sua subsistência, ainda que tormentosa, constitui sinal eloqüente da imersão do Direito do Trabalho numa atmosfera de ruptura paradigmatica" $(1999, \mathrm{p}, 157)$.

7 Os páises, que compóem o MERCOSUL fizeram a opção pela integração para obter uma adequada inserçăo internacional. Projetado a partir de uma dimensão econômica, O MERCOSUL vai sofrendo um déficit quanto às perspectivas sociais, especialmente no que tange às relaçöes de trabalho desenvol vidas no campo regional integrado.

"Octavio lanni diz que "as sociedades modernas, a despeito das suas diversidades e tensóes internas e externas, estāo articuladas numa sociedade global. Uma sociedade global no sentido de que compreende relaçóes, processos e estruturas sociais, econômicas, politicas e culturais, ainda que operando de modo desigual e contraditório" (IANNI, 1995, p. 39).
} 
Estado com o objetivo de amenizar o desequilíbrio de poder entre empregado e empregador na relação laboral, que a regulação do trabalho passou a ter um traço distintivo das regras de Direito comum. As atuais circunstâncias direcionam qualquer análise acerca do tema a um cami nho diverso: deve-se tratar da pertinência do princípio protetor como um paradigma do Direito do Trabalho??

Essas mudanças são de tal ordem, de tal magnitude que, em face da aceleração dos movimentos de integração, o próprio conceito de soberania flexibilizou-se e estamos vivendo, na Comunidade Européia, a soberania compartilhada, na qual os Estados, antes absolutos, compartilham sua soberania com um órgão supranacional. Sem esquecer, em meio a todas essas alterações, a possibilidade de estarmos ante o que se poderia chamar de soberania globalizada ou de globalização da soberania, à medida que nos defrontamos com os perigosos meandros da influência de entidades econômico-governamentais, como o FMI e não-governamentais, como o Clube de Paris ${ }^{10}$.

Trata-se da chamada globalização econômica. No entanto, nada mais é do que uma abertura neo-liberal dos mercados nacionais em prol da interdependência econômica entre os Estados filiados a esta corrente capitalista de desenvolvimento aplicado. Do ponto de vista filosófico, nada de novo foi acrescentado ao modelo mercantilista que impressionou os povos da Europa do início do século XVI ao XVII, quando, então, a navegação marítima, impulsionada por uma tecnologia de ponta, parecia ter realizado o sonho da unificação dos mercados da Europa com o resto do mundo. Com os satélites, telefonia móvel, cabos eletrônicos de fibra óptica e outros acessórios de informática, o processo de globalização obriga a modificar o paradigma das relações internacionais ${ }^{11}$. Várias áreas de decisão, como o campo social, a economia, o meio ambiente, a política e a área cultural,

\footnotetext{
"FREITAS JÚNIOR entende que "o momento da ruptura paradigmática evidencia-se, no campo da dogmática do Direito do Trabalho (como de resto nas demais áreas do Direito e das Ciencias Socinis), precisamente no momento em que os princípios e os postulacios que a caracterizam num deteminado instante de sua evoluçäo, já näo mais conseguem dar conta de ordenar procedimentos cognitivos, nem tampouco de orientar práticas decisórias" (1999, p. 158).

11) Isso vem ao encontro com o que afirmam SEITENFUS e VENTURA, na "limitação saplementar de soberania secundária manifestada através das regras ditas de condicionalidade emitidas pelas instâncias de cooperaçẫo economica e financeira internacionais, como o FMI e o Banco Mundial, que atestam o bon governo (good governance). Para que um Estado-Membro se candidate a receber auxillo dessas instituiçoes é necessário que ele adote uma política econômica que resolva ou atenue os problemas vinculados aos pagamentos externos e à administração interna" (1999, p. 182).

$"$ Pondera GARCIA qque "a retirada do Estado dá-se mais pelo desmantelanento dos serviços (saude, educaçäo) do que pelo efetivo recuo da intervençăo estatal na conduça da política econòmica. Nesse sentido, o livre comércio é produto de exportaçāo ideológico para o terceiro mundo, e năo para o primeiro, onde há fortes protecionismos" (1992, p. 98). A crise do Welfare State reflete o declínio do sindicalismo e dos partidos de esquerta, como consequîencia do fura do padtão tordista de produção e acumulação, que havia permitido no pós-guerra a emergencia de importantes experiências social-democráticas.
} 
que sempre pareceram atinentes ao campo nacional, passam a ser considerados assuntos internacionais. O Estado Nacional está diminuindo, passa a se constituir em um ato secundário de um sistema maior - o sistema global.

Os Estados nacionais devem abrir-se aos principios determinados pelas organizações internacionais: o livre mercado, a iniciativa privada, a liberdade econômica, a saída do Estado do controle de qualquer âmbito que possa ser explorado pela iniciativa privada, a desregulamentação. Estas regras são as que determinarão o auxílio ou não das agências internacionais de crédito, como o Banco Internacional para a Reconstrução e o Desenvolvimento (BIRD) e o Fundo Monetário Internacional (FMI) ${ }^{12}$.

Neste mundo altamente influenciado pela tecnologia, no qual o Brasil busca inserção, e nós, seus habitantes, procuramos encontrar nosso espaço, como ficam as relações de trabalho, e, sobretudo, os princípios que histórica e doutrinariamente constituem o Direito do Trabalho? ${ }^{13}$

Com o agravamento do desemprego, os partidários do neo-liberalismo difundem idétas flexibilizadoras da normas trabalhistas como forma de aumentar o número de empregos. Justificam a diminuição e/ou supressão das obrigações dos empregadores, dos encargos sociais, como a única maneira de ampliar postos de trabalho. Não é por acaso que se coloca por terra um direito protetivo, as normas de direito público, a impositividade do Direito o Trabalho ${ }^{14}$. Essa política

\footnotetext{
"En relação à crise do Estado social esclarece Norberto Bobbio: "a crise do estado assistencial é o eferto tambem do contraste entre o empreendedor economico, que tende à maximização do lucro, e o empreendedor econômico, que tende à maximizaçâo do poder através da caça aos votos. (...) No fundo, a exigència expressa pelo neoliberalismo é a de reduzir a tensão entre os dois, cortando as unhas do segundo e deixando o primeiro com todas as suas garas afradas. En suma, para os neoliberais a democracia é ingovernável nẫo só da parte dos governados, responsáveis pela sobrecarga das demandas, mas também da parte dos governantes, pois estes näo poden deixar de satisfazer o mator número para fazerem prosperar sua empresa (o partido). Pode-se descrever sinteticamente este despertar do liberalismo através da seguinte progressão (ou regressão) histórica: a ofensiva dos liberais voltou-se historicamente contra o socialismo, seu natural adversário na versão coletrista (que é, de resto, a mais autêntica); nestes últimos anos voltou-se também contra o Estado do Bem-Estar, isto é, contra a versão atenuada (segundo uma parte da esquerda tarnbèn falsificada) do socialismo agora é atacada a democracia pura e simplesmente. A insidia é grave. Não está em jogo apenas o Estado Bem-Estar, quer dizcr, o grande compromisso histórico entre o movinento operário e o capitalismo maduro, mas a própria denocracia, quer dizer, o outro grande compromisso histórico precedente entre o tradicional privilegio da propriedade e o mundo do trabalho organizado, do qual nasce direta ou indiretamente a democracia moderna (atraves do sufrágio universal, da formagăo dos partidos de massa, etc)" (BOBBIO, 1986, p. 126).

${ }^{13}$ Ressadta Palomegue López que "el elemento que se desea introducir en el sero del debate que nos ocupa es, más bien, una llamada de atención sobre las verdaderas ráces visibles en la operación de, a través de un proceso general de culpabilización del Detecho del trabajo y de sus instituciones propias, desarme de la funcion y senas de identidad esenciales del orden juridico-laboral y asalto neoliberal a la ciudadela del garantismo de los derechos de los trabajadores, fatigosamente conseguidos a lo largo de la historia e hoy ya patrimonio común del modemo Estado social de derecho (...) al amparo de supuestas exigencias de la crisis económica, cuando es así que, diversamente este proceso dista de imponer tales conclusiones de forma conceptual y necesaria" (PAXOMEQUE, 1984, p. 17-18).

it Rivero Lamas declara que do Direto do Trabalho exigese que se tome "un instrumento al servicio de la política de empleo, que no obstaculice la incorporación de los avances tecnológicos y que dé cabida a nuevas formas de trabajo en un order económico mundial cada vez más abierto e drversificado" (RIVEO, 1996, p. 969-970).
} 
flexibilizadora se dá justamente para atender às determinações de um processo globalizador que promete conseqüências benéficas e prosperidade, permite que os países participem das grandes inovações tecnológicas, abre as fronteiras para os investimentos, para os financiamentos, para o comércio internacional em troca do afastamento do Estado das questões trabalhistas e sociais.

Como consequiência da inserção do Estado no sistema global é necessário que se façam os ajustes, que se atendam as determinações de um processo, a ausência de regras. Tem-se, dessa forma, a volta da liberdade entre empregados e empregadores, a igualdade entre as partes, que livremente contratam as regras de seu contrato, sua jornada, seu salário, suas horas extras, entre outros, como meio de fomentar a ampliaçăo de empregos; porém, o pano de fundo é o processo globalizador, que determina as regras do jogo. Percebo que a proteção jurídica do trabalho, do momento inicial da concepção tutelar, cedeu lugar, desde meados dos anos 1960, a uma concepção autotutelar, caracterizada pela flexibilização ${ }^{15}$.

Essas alterações são, sobretudo, originárias de causas estruturais e conjunturais. As causas conjunturais, ao meu ver, decorrem dos encargos sociais, das diferenças cambiais, das taxas de juros, da falta de investimentos no campo. As estruturais são a globalização da economia, a falència do Estado, a obsolescência do Direito ${ }^{16}$. E quais são as alterações que verifico, geradas por essas causas? Conjunturalmente, as crises conômicas; estruturalmente, as novas tecnologias. E a conseqüência? A necessidade de rever a postura dos cientistas sociais, dos dirigentes das organizações públicas e privadas, dos líderes políticos e comunitários. Ora, esse quadro pincelar oferece uma macro visão do mundo.

\footnotetext{
"Sappia defende que "...viene acompañada de una fuerte ofensiva ideológica (de contenido neoliberal) que va dirigida a restablecer en términos absolutos la vigencia de la autonomia de woluntad de las partes dentro del contrato de trabajo, to que sin lagar a dudas generaría una nueva hegemonía del capital. En esa postura se dice la legislación laboral os la causante de la crisis económica y de la pérudida de chiciencia y competitividad de las empresas" (SAPPIA, 1996, p. 2).

t" No mesmo scatido, Ney Prado entende que "de que servem, afinal, para a maioria dos marginalizados da lei e da fortuna dispositivos constitucionais como a particípaça nos lucros (art. 7 a , XI), licença à patcrnidade (art. 7*, XXVI) ou a proibiçã̃o de distinção entre trabalho manual, técnico ou intelectual (art. 7: XXXII), para ficamos nesses exemplos, se tudo o que necessitam os legítimos é um minimo de proteça que thes permita continuar trabalhando, obter cmpregos e sustentarem-se num país ral e não num país utópico, só existente no papcl?" (PRADO, 1991. p. 103).
} 
Na sociedade atual, os parceiros sociais têm tentado encontrar meios para solucionar seus conflitos, suas divergências e suas necessidades ${ }^{17}$.

O trabalhador busca uma ocupação onde possa obter recursos para sustentar a si e a sua família. Muitas vezes abdica de certos privilégios e previsões legais para poder sobreviver com o mínimo de dignidade. Por isso, o Direito do Trabalho cogita de flexibilizar as normas que protegem o trabalhador, para poder, ao cabo, garantir a sua sobrevivencia. Deve, contudo, haver a preservação de um standard mininum que the proporcione (ou, em muitos casos, restitua) a dignidade. Dessacralizar mesmo as memórias mais caras de acontecimentos ou fatos do século XX é a desfaçatez intelectual do revisionismo. $\mathrm{O}$ ramo juridico mais exposto a incursões corsárias é o de Direito do Trabalho ${ }^{18}$.

Aos olhos dos críticos hodiernos do capitalismo, a globalização confirma a persistente validade da intuição que relampejou Friedrich Hayek, em "O Caminho da Servidão" (1944), considerado arauto da globalização porque ali descreve cenários de que não havia quaisquer vestígios: a indústria de base que declina, Nações que são obrigadas a satisfazer a exigência de adaptar-se ao mercado global, processos econômicos que se desenvolvem de maneira incontrolada em nível planetário. Enfim, tinha compreendido com grande antecedência que a sociedade transformada pelo capitalismo está destinado a ser tornar, pelas tendências aprisionadas de longo período, o modo industrial de produzir em uma fase temporária na história da humanidade, destinada a ser substituída por uma fase no decurso da qual codificar-se-ia uma outra sociedade. Um mundo semelhante àquele que está crescendo sob os nossos olhos. Uma sociedade anunciada, portanto ${ }^{19}$. Não obstante isso, diante dela sentimo-nos indefesos. Estamos

\footnotetext{
Falienta Canotilho que "no âmbito político assiste-se ao refuxo da política formal (do Estado, dos parlamentos, dos governos, das burocracias, das formaçoes socias rigidificadas); no dotninio jutidico, o espetáculo é o refuxo juridico (deslocaçấo da produçẩo normativa do centro para a periferia, da le para o contrato, do Estado para a Sociedade). (CANOTLLMO, 1994, p. 391).

is Diz Coutinho: "o processo de reengenharia de um novo perfil de empregado, deixando de lado o paradigma do empregado referéncia da CLT, subordinado, apenas destinatirio do poder de comando e direção, para adotar o trabalhador eficiente, produtryo, que assume responsabilidades age independentemente do comando, atendendo is demandrs do mercado, em uma estrutura de organizaçăo flexivel. O controle da ativitade desempenhada, objeto do contrato de trabalho, que era identificado como um controle simples, através de dominaçẫo afbitrária e personalista, exercido com mecanismos de coerçäo - poder punitivo, disciplinador - passa a ser complexo, caracterizado pela impessoalidade de empresas internacionalizadas en alta concentraço de capital e pela naturoa condicionada e compensatóna. A subordinaç̃o tomese prescindvel, e a força de trabalho é menos relevante do que o resultado desta" (COUTNHO, 1999, p. 9).

"Entende Maria Margareth Garcia Vieira que "a grande inovaço desse novo modelo para a organização da afividade industrial é a produção por demanda. É o consumo que determina a produção e não o inverso. A reposição dos estoques é feita somente após a verificação da demanda que existe no mercado, sendo que em tempo de falta de demanda a unidade fabril trabalha apenas com um nucleo de trabalhadores polivalontes, cujo tempo de trabalho é aprovetado ao máximo. Esse núteo de trabalhadores orzanizado de forma horizontal para gue haja aproveitamento maximo de conhecimentos, habilidades $e$ responsabilidades. Fn épocas de amento de denanda no mercado, o trabalho da unidade fabril é reforçado por trabathadores contratados por prazo determinado ou atraves de empresas interpostos" (VIEIRA, 2000, p. 52 ). 
desorientados. Forçosamente. Não tendo a filosofia otimista da história que sustenta Marx e Engels, corremos o risco de permanecer esmagados por um profundo pessimismo cósmico. Globalização é uma palavra que compete com palavras como flexibilidade e com o neo-liberalismo. Em tudo isso não há nada de conjuntural e extemporâneo.

$\mathrm{Na}$ realidade, o neo-liberalismo não é senão a síndrome da crise não resolvida do Estado tardio-liberal do século XIX e, portanto, não é outra coisa senão um neologismo para exterminar o legado hereditário do melhor sindicalismo euro-continental que, de Weimar em diante, lutou para dar vez às classes mais fracas, para redistribuir poder e riqueza.

Antes que a palavra globalização, entendida como forma extrema de flexibilidade de todos os fatores produtivos, contaminasse, no dizer de Umberto Romagnoli, a linguagem dos juristas, até há poucos anos, na Europa, do Direito do Trabalho se falava todo o bem possível.

Dizia-se que é um dos poucos exemplos indubitados do progresso da cultura jurídica moderna porque forçou os ordenamentos dos Estados e indicou as doutrinas jurídicas - a não perder de vista que, enquanto todos os contratos têm em vista somente o ter das partes, o contrato de trabalho tem em vista, em primeiro lugar, o ser do trabalhador. Dizia-se que o trabalho era o Direito do século, porque o século XX era o século do trabalho, da busca dos equilíbrios que correspondessem à necessidade - se não a intenção - de colocar o trabalho assalariado e o capitalismo industrial em uma relação de condicionamento recíproco em vista de vantagens recíprocas.

O século XX foi o século breve: começou tarde, terminou $\log ^{20}$.

O Direito do Trabalho está atravessando um processo de adaptação a uma situação alterada, na qual os trabalhadores estão aprendendo a pretender a restituição da capacidade de autonomia privada coletiva necessária para a gestão dos próprios interesses sem paternalismos legais, nem garantismos coletivo-sindicais ${ }^{21}$.

\footnotetext{
29 Umbero Romagroli afirma que: "...se bem que não era senão uma ponte - construida com a técnica dos castores, andar por andar, um pouco de cada vez - para unir o século precedente com o subsequiente, o Direito do Trabalho do século XX entrará no terceiro milênio com a dúvida de ter conservacio o none, mas não a razão das origens. A propósito, as opinióes expressas pelos juristas de todos os paises (não só europens) têm a característica do pensamento único" (ROMAGNOLI, 2001, p. 26).

21 Para Jorge Luiz Souto Maior, "a luta de classes trava-se principalmente no mundo dis ideias. A atual crise das idèas faz com que os trabalhadores não consigam mais se mobilizar. Na substituiçāo do homem pela máquina, o valor do trabalho é diminuido e com cle diminui a importancia dos direitos dos trabalhadores. Surgem idéias baseadas no paradigma da livre concorrência e não no paradigma da solidariedade. Com isso, flexibilização e destegulamentação voltam a ser noçóes de direito e não de liberdade" (SOUTO MAIOR, 2000, p. 23).
} 
Acredito que a flexibilização nas relações de trabalho não só transfere para os trabalhadores boa parte dos riscos empresariais (toyotismo) como os transforma em seus próprios algozes. São eles responsáveis pelos bons resultados da exploração da própria força de trabalho, e pelo recolhimento da mais-valia dela resultante. Todos esses sentidos (flexibilidade de formas de contratação, de dispensa, de tempo, de local, de função) soam como ineludível indício de ruptura de paradigmas. $O$ paradigma do Estado Social transposto para o Direito do Trabalho, que baseou-se na proteção de condições de trabalho da organização taylorista/fordista, não é mais suficiente para responder às mudanças sociais, políticas, ideológicas e tecnológicas do nosso tempo.

No paradigma democrático, a fixação de linhas diretivas e de princípios de natureza teorética, necessários para a admissão de uma flexibilização com ele compatível, postula, talvez, um modelo completamente novo de práxis científica.

Nesse modelo devem incluir-se não somente outros métodos utilizados pela sociologia, economia e filosofia, como também com outros ramos do Direito, em especial o Direito Constitucional, principalmente mediante a resolução de antagonismos entre princípios, ou entre princípios e regras, pois a interpretação do Direito material e processual do Trabalho não tem possibilitado essa integração.

Via de conseqüência, os problemas do Direito Constitucional do Trabalho não podem ser equacionados se os arquétipos paradigmáticos continuam a ser os do Estado liberal, ou mesmo do Estado social, este, porém, fundado na organização do trabalho segundo, exclusivamente, o modelo taylorista/fordista.

Eis porque novos conceitos (telecomutação, trabalho informal, trabalho precarizado, subordinação jurídica, dentre outros) precisam integrar-se no ordenamento jurídico, ou serem por ele revistos, pois o reconhecimento da realidade e o seu redirecionamento pelo Direito dependem primeiro do estudo de características, conceituação, previsão e conformação legal a certos requisitos, e do estabelecimento de mecanismos de proteção jurídica.

O paradigma do Direito do Trabalho está em ruptura ${ }^{22}$. Ele não responde às

\footnotetext{
${ }^{22}$ Manucl Ramón declara que o princípio protetor ou pro operario têm quatro funções: "1. Función directiva general de todo el proceso de creación del Derecho, condicionando el contenido que haya de darse a las normas jurídicas en trance de claboración; 2. Función interprctativa, según la cual los principios sirven para precisar el significado de las normas escritas y su sentido o finalidad, así para ampliar o reducir su ámbito de vigencia o incluso para excluir su aplicación; 3. Función integradora de las lagunas del sistema normativo (...) que permite al Jucz resolver en Derecho los conflictos que se plantean en ausencia total de norma escrita (y de costumbre, allí donde ésta es aplicable); 4. Función constructiva, limitada al puro ámbito doctrinal, pero no por ello menos importante. En este plano, los principios actúan como estructuras mentales que permiten la sistematización de la materia jurídica" (ALARGON CARACUEL, 1990, p. 863). 
necessidades de se fazer um Estado social fundado na universalidade de direitos e não nos direitos de corporaçōes regidas por contratos de trabalho.

O Direito do Trabalho do século XX já entrou em rota de coalizão [al8]com uma invisivel lex mercatoria que, redesenhando a geografia econômica inteira, ameaça desnacionalizá-lo não tanto no final de um processo de adequação transnacional orientado à conservação da sua identidade originária, mas sim no final de uma ruinosa concorrência para o rebaixamento entre os direitos nacionais.

Umberto Romagnoli afirma:

"morrerei convencido que as democracias são devedoras para com o moderno Direito do Trabalho porque - se sobreviveram no século da revolução industrial e até se expandiram, consolidaram, aperfeiçoaram - devemno à estabilidade social que o Direito do Trabalho contribuiu para assegurathes, introduzindo medidas compensatórias aos inquilinos que ocupam os andares baixos do edificio social".

O homem-trabalhador deve ser visto como o sujeito-fim e não objetomeio do desenvolvimento. Não devemos pensar em criar mais direitos, mas dar garantia para a eficácia do que já existem. Como alerta Norberto Bobbio, "o problema fundamental em relação aos direitos do homem, hoje, não é tanto o de justificá-los, mas o de protegê-los. Trata-se de um problema não filosófico, mas político." ${ }^{23}$.

Devemos ter como paradigma os princípios do Direito do Trabalho apresentados por Plá Rodrigues: protetor, irrenunciabilidade, continuidade, primazia da realidade, razoabilidade e boa-fe ${ }^{24}$. Contudo, a questão pontual é que o homem começa a se internacionalizar, globalizar, mundializar. E a ter menos importância para a humanidade que a própria máquina que ele criou. Talvez aqui esteja o maior equívoco: ao criar a máquina, o homem, ser imperfeito, não o fez à sua imagem e semelhança, por isso corremos o risco de não conseguir alcançar o verdadeiro sentido de um verbo menos importante que é misericordiar, mas que exige a nossa reflexão.

\footnotetext{
23 F acrescenta: "não se trata de saber quais e quantos säo esses direitos, qual è sua hatureza ê sea fundamento, se são direitos naturais ou históricos, absolutos ou telativos, mas sim qual é o modo mais seguro de garanti-los para impedir que, apesar das solenes declaraçốes, eles sejam continumente violados" (BOBBIO, 1992, p. 25).

2. Raffadc De Luca pontua a necessidade da vinculaçăo da negociação a direitos fundamentats dos trabalha dores: "essa è il frutto piuttosto del corposo rilievo che il dilagare della mediazone autônoma o, comunque, non a caratcre generale - disancorata da un quadro di rifermento legale o quanto meno da precise regole del yioco - rischia per un verso di coinvolgere, nello storzo di compromissione degli interessi, dirtti fondamentali del lavonatore e per un altro de incidie pesantemente sugli interessi della collettivita dei cittadani o di queli non adequatamente rappresentati dai grandi gruppi organizzat" (TAMAJO, 1982, p. 51).
} 
Os paradigmas da flexibilização são os mesmos que embasam o Estado Mínimo. $O$ distanciamento do aparato estatal da proteção do trabalhador é visto pelos defensores da flexibilização como um avanço da democracia, no sentido de que são agora não mais os trabalhadores, classe oprimida, mas sim cidadãos, os partícipes da negociação contratual. É o cidadão quem deve dizer o que é melhor para ele, e o Estado somente prejudica essa cidadania intervindo nas relações sociais, ao ponto de sufocar a iniciativa no campo econômico.

Já os que são contrários à flexibilização, entre os quais me filio, vêem nos seus fundamentos um retorno ao Estado liberal, que não levava em conta a igualdade substancial, mas tão somente a igualdade formal.

O fundamento histórico e ideológico da flexibilização está na derrocada do socialismo (que embasava a sustentação do paradigma da igualdade substancial implantado no Estado Social); o fundamento econômico, na revolução tecnológica (que possibilitou expansão do capital pela via das comunicações e vem incrementando a substituição do homem pelo robô); o fundamento social, na nova organização, ou reestruturação do trabalho na forma toyotista de produçâo (que inviabiliza a noção de classe); o fundamento político, na crítica à ingovernabilidade das democracias baseadas no Estado keynesiano e no mercado de votos.

$O$ conjunto desses fundamentos faz com que os conceitos, institutos e fundamentos do Direito do Trabalho ${ }^{25}$ sejam insuficientes ou inadequados para as novas relações de trabalho e, ante a falta de um modelo a seguir, a flexibilização apresenta-se como a solução que põe fim à inadequação deste ramo jurídico, acabando com ele e transferindo a resolução para a esfera privada.

A flexibilização, como decorrência de uma ruptura paradigmática, faz com que o princípio protetor do Direito do Trabalho (norma mais favorável, condição mais benéfica e in dubio pro operário) deixa de ser apenas um ato de emendar ou não a Constituição, e possa a ser o enfrentamento das conseqüências dessas propostas sobre os direitos fundamentais de sustentação do Estado democrático.

\footnotetext{
3. Palomeque Lópes pondera que "lo que, sin embargo, no se está en condiciones de probar de modo suficiente todavía es que asistamos a una mutación de los objetivos esenciales de la propia disciplina, ni se siquiera que nos dispongamos a enterar alegre y definitivamente cuantos postulados han acompañado al Derecho del trabajo en buena parte de su recorrido bistorico. La actitud más prudente ante las transformaciones ciertas que la crisis económica viene provocando en el andaime juridico laboral sigue siendo la de recogida y valoración cuidadosa de los ingredientes en juego, sin empezar por el momento, the parece, juicios de alcance definitivos, $y$, sobre todo, la de separación de lo que pueden ser conclusiones experimentalmente viables y lo que, tan sólo son intentos interesados de utilizacion de la crisis econónica, o propuestas que, bajo el ropaje aparente de verdades científicas, no hacen, sino encubrir pura idcologia" (PALOMEQUE LOPEZ, 1984, p. 15-16).
} 
Voltemos nosso olhar e nosso pensamento para o futuro do mundo.

No momento em que a capacidade estatal de garantir a segurança dos cidadãos começa a ser rompida, em que a mundialização da economia enfraquece o Estado e começa a se questionar a existência mesmo do Estado Nacional, em que a soberania cede lugar a forças transnacionais que rompem todos os padrões de respeito pela pessoa humana, precisamos refletir sobre nós, as nossas instituições e o nosso futuro, antes que ele chegue e termine.

A proposta de desestadualizar e desterritorializar o governo do mercado de trabalho é mais perigosa do que possa parecer. Seguramente, não é senão uma tardia reação à frigidez social de instituições desestadualizadas e desterritorializadas como o FMI, o Banco Mundial, a Organização Mundial para o Comércio, sobre cuja praxe operacional a OIT demonstrou não estar em condições de influir.

Por isso, agrada-me interpretar que a Resolução de 18 de junho de 1998 da OIT é essa testemunha que a estação dos direitos nacionais está terminando por manifesta inadequação da soberania territorial dos Estados em fazer valer as razões universais dos valores humanitários; ao mesmo tempo nos indica a esperança que possa iniciar a idade da sua desnacionalização.

\section{BIBLIOGRAFIA}

ALARCÓN CARACUEL, Manuel Ramón. La Vigência Del Principio "Pro Operário". In: MELGAR, Alfredo Montoya et al. Cuestiones Actuales de Derecho Del Trabajo. Estúdios ofrecidos por los catedráticos españoles de Derecho Del Trabajo al professor Manuel Alouso Olea. Madrid : Centro de Publicaciones Ministério de Trabajo y Seguridad Social, 1990.

BOBBIO, Norberto. O futuro da democracia: uma defesa das regras do jogo. Trad. Marco Aurélio Nogueira. 4.ed. Rio de Janeiro : Paz e Terra, 1986. A era dos direitos. Trad. Carlos Nelson Coutinho. Rio de Janeiro: Campus, 1992. BONAVIDES, Paulo. Do País Constitucional ao Pais Neocolonial. São Pau1o: Malheiros, 1999.

CANOTILHO, José Joaquim Gomes. Constituição dirigente e vinculação do legislador. Contributo para a compreensão das normas constitucionais programáticas. Coimbra : Coimbra, 1994.

COUTINHO, Aldacy Rachid. Direito do Trabalho: a passagem de um Regime despótico para um regime hegemônico. Revista da Faculdade Mineira de Direito, n.3 e 4, v.II, 1999.

DE LUCA TAMAJO, Raffaele. Garantismo Legislativo e Mediazione Político-Sindicale: prospettive per gli ansi 80. Revista Italiana di Diritto Del lavoro, 
Anno 1, 1982.

DE MASI, Domenico. O futuro do trabalho: fadiga e ócio na sociedade pós-industrial. Trad. Yadyr A. Figueiredo. Rio de Janeiro : José Olympio; Brasilia : Ed. da UnB, 1999.

FARIA, José Eduardo. O Direito na Economia Globalizada. São Paulo, 1998. Tese (Professor Titular) - Faculdade de Direito, Universidade de São Paulo. FREITAS JÚNIOR, Antonio Rodrigues de. Globalização, Mercosul e Crise do Estado-Nação: perspectivas para o Direito numa sociedade em mudança. São Paulo : Ltr, 1997.[al9]

Dircito do Trabalho na era do desemprego. Instrumentos jurídicos em políticas públicas de fomento à ocupação. São Paulo : Ltr, 1999.

GARCIA, Marco Aurélio. Uma história sem fim. Tempo e História. Adauto Novaes (Org.). São Paulo: Companhia das Letras, 1992.[al10]

IANNI, Octavio. A Sociedade Global. Rio de Janeiro : Civilização Brasileira, 1995.

OLEA, Manuel Alonso. Lãs Fuentes Del Derecho, em Especial Del Derecho Del Trabajo Según la Constitución. Madrid : Civitas, 1982.

PALOMEQUE LOPEZ, Manuel-Carlos. Um Compañero de viaje histórico del derecho del trabajo: la crisis económica. Revista de Política Social, n.143, jul. sept. 1984.

PRADO, Ney. Economia informal e o direito no Brasil. São Paulo: Ltr, 1991.

RIVERO LAMAS, Juan. Poderes, libertades y derechos en el contrato de trabajo. Revista Española de Derecho del Trabajo, n.80, nov. dic. 1996.

ROMAGNOLI, Umberto. Os juristas do trabalho frente à globalizacão. Trad. Mariano Czaikonski. In: SLLVA, Diana de Lima e; PASSOS, Edésio (Coord.). Impactos da globalização: relações de trabalho e sindicalismo na América Latina e Europa: teses do grupo de Bologna/Seminário Internaciom nal do Direito do Trabalho. São Paulo : LTr, 2001.

SAPPIA, Jorge J. et al. Empleo y Flexibilidad Laboral. Leyes 24.465,24.467 y sus reglamentaciones. Período de prueba. Trabajo a tiempo parcial. Fomento del empleo. Contrato de aprendizaje. Régimen de la pequeña empresa. Buenos Aires : Astrea, 1996.

SEITENFUS, Ricardo; VENTURA, Deisy. Introdução ao Direito Internacional Público. Porto Alegre : Livraria do Advogado, 1999.

SILVA, Floriano Corrêa Vaz da. Direito Constitucional do Trabalho. São Paulo : Ltr, 1977.

SOUTO MAIOR, Jorge Luiz. O direito do trabalho como instrumento de justiça social. São Paulo : LTr, 2000.

VIEIRA, Maria Margareth Garcia. A Globalização e as relaçōes de trabalho. Curitiba : Juruá, 2000. 